\title{
Oscar Castro Z. Perfíl Criollista de sus Cuentos
}

Entre los rasgos más acentuados de la novela chilena de los últimos cincuenta años se destaca el afán constante de los escritores por descubrir y aprehender la fisonomía de la tierra y su gente con miras a vaciarla, con toda la palpitante vitalidad que posee, en los moldes personales de creaciones artísticas nacionales. Esta noble ambición literaria exige, desde luego, disponer de algunos recursos imprescindibles de cuyo mayor o menor dominio depende, como siempre lo ha sido, el valor estético de toda obra creada. Por una parte, se hace preciso contar con la oportunidad de haber conocido y la capacidad de haberse asimilado el contenido vital del medio físico y humano en todas su facetas y dimensiones, no tanto en extensión cuanto en profundidad. Por otro lado, aparte del talento natural o espontáneo del genio creador, se requiere un cierto grado de cultura sistemática y disciplinada que, amalgamándose con las dotes personales del autor, permita proporcionar el cuidadoso e inconfundible toque genial que ha de poseer la matriz artística.

En el abultado repertorio de cuentistas y novelistas chilenos del siglo Xx muchos son los que se han lanzado a la empresa de captar el alma de su tierra y su gente para inmortalizarla en las letras. Algunos autores han pretendido abarcar un ámbito físico y humano demasiado amplio sin percatarse de que el escenario de Chile, por su rica variedad tonal, es casi imposible de constreñir dentro de los estrechos límites de un simple brochazo artístico. Otros, conociendo bien su propio "rincón", han revelado manifiesto retardo literario novelando en pleno siglo $\mathrm{xx}$ a base de cansadas técnicas de la pasada centuria. No han faltado tampoco los que falseando una materia nunca vista, $y$, por lo tanto, incomprendida hasta el extremo de no haber sido jamás sentida, han llegado, no obstante 
lo genial de su concepción y en parte talentoso despliegue de recursos formales, a lamentables excesos de artificialidad. La falta de buen gusto, la carencia de formación artística, por no decir apresurada improvisación, y el osado atrevimiento para apoderarse del interés del lector medio, muchas veces gracias al apadrinamiento de incultos revisteros, han constituido fenómenos que debieran obligar al crítico serio a meditar constructivamente acerca del verdadero mérito del cuento y la novela de Chile en el siglo XX. Pululan en las letras de ese país, como en la de muchos otros hispanoamericanos, escritores que desconociendo la materia, careciendo de cultura o demostrando escaso talento creador han monopolizado las prensas y la atención del público con visible menoscabo de obras, cuyos méritos artísticos las hacían merecedoras de amplio apoyo y difusión.

Afortunadamente las letras iberoamericanas pueden hoy contar con figuras literarias chilenas, cuya meritoria producción se destaca en el país $y$ en el continente con inconfundible claridad. Hay, por otra parte, valores nuevos que aún permanecen casi perdidos en el estrecho marco del territorio nacional en circunstancias de que su labor ha rendido óptimos frutos artísticos. Entre estos autores casi desconocidos, no obstante el significado de sus obras dentro de la llamada "nueva generación" de prosistas, se encuentra la figura de Oscar Castro, indiscutiblemente una de las más notables de los últimos veinticinco años. A pesar de la brevedad de su vida física, la inspiración que legó con su producción es de inapreciable valor y grandes proyecciones.

Castro fue hombre de su tierra provinciana y de su rincón rancagüino, donde nació el 25 de marzo de r9ro y en el que permaneció hasta terminar los estudios de humanidades.

Muy pobre, de la clase más modesta, se formó solo, luchando en condiciones penosas, capaces de corromper y amargar al mejor templado; pero estaba hecho de piedras preciosas y conservó firme e intacta la pureza de su espíritu, la bondad de su corazón. ${ }^{1}$

Castro vivió una vida bohemia y azacanada en su ciudad natal, que uno de sus biógrafos ha descrito como "un puerto sin mar y sin orillas", junto a una montaña de cobre, lugar de paso, adonde "Ios hombres llegan, viven un tiempo en cualquier forma y se van". Estas circunstancias hicieton más áspero aún para un hombre de sensibilidad aguda como era Cas-

1 Alone, Historia personal de la literatura cbilena (Santiago de Chile, Zig-Zag, 1954), p. 236. 
tro, el ambiente ya de por sí poco alentador para los artistas que hay en las ciudades provincianas. ${ }^{2}$

Los estudios de pedagogía que luego prosiguió en la Universidad de Chile pero sin titularse de profesor, lo llevaron a la bulliciosa capital y lo indujeron a desempeñar diversas ocupaciones en bancos, bibliotecas y rotativos. A la postre, sin embargo, remató en su patria chica, donde ejerció la profesión de maestro de castellano, en el Liceo de Hombres, hasta poco antes de su muerte, el Io. de noviembre de I947.

Uno de sus biógrafos, Gonzalo Drago, nos describe así al joven escritor:

Conoci a Oscar Castro en 1930, en la ciudad de Rancagua... Era un hombre modesto, sencillo, cordial, pulcro, sin que nada denunciara exteriormente el auténtico poeta que ocultaba su envoltura carnal. Al mirarlo por primera vez, nadie habría sospechado que ese hombre de mirar apacible y lentas actitudes, era el dueño de un enorme y maravilloso caudal de emociones y experiencias poéticas, que lo llevaron hasta las cimas de la celebridad, sin que perdiera la modestia que lo caracterizaba.

Tenía una cultura poética poco común. Sediento de lecturas, supo nutrirse en las mejores fuentes literarias..., tenía un conocimiento completo de los clásicos españoles. Podríamos decir que gran parte de su vida pasó rodeado de libros. En los estantes y rincones de su casa, en la Biblioteca de Geyter de Rancagua, en el salón de lecturas del Liceo de Hombres, su silueta frágil estuvo siempre curvada frente a un libro abierto.

En la ciudad minera era un espíritu solitario y erguido frente a la indiferencia de los más y la reticente aprobación de los menos. Como un modesto $\mathrm{y}$ resignado artífice, continuaba creando y puliendo sus versos en una acogedora casa de arrabal donde llegaban de tarde en tarde algunos escasos amigos. 3

En I936 su nombre se hizo conocido en los círculos literarios a raíz de unos versos que leyó en la velada de homenaje que se tributó en Valparaíso al malogrado poeta Federicu García Lorca. El prestigio que se conquistó en aquella ocasiór rino a afianza: el que ya gozaba en el círculo de sus amigos y le abrió la senda de la fama que adquirió como poeta al publicar Camino en el alba (1940, prologado por Augusto d'Halmar, Viaje del alba a la nocbe (1940), Las alas del Fénix . Romances de una ciudad beroica (I943), Reconquista del bombre (1944), Ho.

2 A. M. [Alejandro Magnet], "Un poeta cuentista", prólogo de Comarca del jazmin y sus mejores cuentos (Santiago de Chile, Edit. del Pacífico, 1953), p. 7.

3 Gonzalo Drago, "Vida y obra de Oscar Castro Z.", Atenea (Concepción, Chile), 1948, Nos. 271-272, pp. 37-38. 
rizonte (1944), Glosario gongorino, sonetos (I944), y varios tomitos antológicos en que evidenciaba su originalidad, pues "mientras seducidos por García Lorca, otros se quedaban en un mundo de limoneros, verdes lunas y gitanerías más o menos disfrazadas, Castro supo captar lo valedero de la lección del maestro: el redescubrimiento de lo popular y su expresión en el ritmo ágil y la rápida imagen del viejo y popular to. mance". 4

Es digno de observarse que aunque la crítica elevaba a Castro a altos sitiales con premios y loas, el joven autor no perdió en ningún momento ese sentido de las proporciones y esa dedicación al arte que, como requisito indispensable, parecen exigitle al creador un cierto retraimiento y una vuelta silenciosa a la intimidad de su auténtico ser. Sabemos que desde 1933 Castro auspiciaba el círculo literario rancagüino llamado "Los Inútiles", en el cual entre los amigos de más confianza, daba lecturas a sus composiciones.

Oscar Castro, sin pontificar, era una lámpara encendida en el centro de "Los Inútiles", iluminando con su presencia la vida de sus compañeros. Jamás tuvo actitudes de conductor, de jefe... Tenía el don de la sencillez. Su palabra llana carecía de toda inflexión de prepotencia. Sonriente decía crudas verdades en la intimidad del grupo o dondequiera que su opinión era requerida. Se burlaba de los convencionalismos, de los prejuicios, de los políticos profesionales y de la estupidez humana cuando alcanza caracteres colectivos...

Jamás tuvo la cobardía de callar sus ideas. Porque fue un idealista puro que no perteneció a ninguna secta, militó en ningún partido... Fue un hombre libre que supo alternar con el más humilde despojándose de todo su lenguaje enriquecido por la lectura para hacerse comprender por aquellos que sólo balbuceaban frente al gran libro de la vida. ${ }^{5}$

Obsequiado con los mejores galardones, en I939 lo premió en la Argentina la Asociación de Educadores Liniers, en tanto que la revista Atenea y la Municipalidad de Santiago se apresuraban a tributarle codiciados honores. La apoteósica ceremonia pública del I7 de junio de I945, en que la Municipalidad de Rancagua le declaró hijo ilustre de su pueblo natal y le entregó una medalla de oro que simbolizaba el aprecio con que se le distinguía, se dice que fue memorable. Pero estos honores y otros que sería largo enumerar no consiguieron modificar su firme determinación de dedicarse con lentitud y seriedad al trabajo literario. De alli que

\$ A. M., "Un poeta cuentista", cf. No. 2, p. 8.

5 Gonzalo Drago, "Vida y obra de Oscar Castro Z.", cf. No. 3, pp. 39-40 
su labor sea relativamente escasa y que las composiciones que logró terminar sean por lo general acabadas y finas. Largas horas de estudio y de elaboración destinadas a disciplinar su genio y modelar sus experien. cias y concepciones son el balance más provechoso y ejemplar que Castro tiene a su haber. Su afán de superación era grande, su interés por per. feccionar sus obras se nos revela intenso y su ansiedad por escuchar la voz de la crítica nos parece una preocupación más obsesionante que el vano placer por muchos buscado de cosechar fáciles aplausos. En las cartas dirigidas a Hernán Díaz Arrieta ${ }^{6}$ se observa esta profunda conciencia que poseía Castro de la misión que veía trazada para sí en la tradición literaria chilena y el dolor que experimentaba al dar uno que otro traspiés. Esta actitud comprensiva ante la crítica adversa, el deseo de cambiar de rumbos tras nuevos derroteros y la mejor disposición a apartarse de todo posible fracaso por las imperfecciones que pudieran deslizarse en el cuidadoso tejido artístico que anhelaba producir llevaron a Castro a pulir y modificar sus obras con un gran sentido de pulcritud estética. Las largas horas de trabajo y estudio con seguridad agudizaron su mal y presa de una incurable afección pulmonar pasó a mejor vida dejando inéditas algunas de las novelas que en años recientes han sido publicadas póstumamente. En éstas, sólo por comparaciones con obras precedentes es posible notar caídas que, de haber sido Castro un escritor negligente, hubieran pasado desapercibidas o justificadas con el acostumbrado disfraz de "espontaneidad" o "signos de nuestros tiempos".

Es indudable que la cultura literaria de Oscar Castro, su vasto y profundo conocimiento de los mejores autores clásicos y modernos, como asimismo la tonificante compañía de los profesores que guiaron sus pasos y alimentaron sus gustos con las lecturas más provechosas del repertorio hispánico, han dejado una huella innegable en el culto espíritu del prosista rancagüino. Nada hay en él de las estridencias formales, ni de las chabacanerías, obscenidades e innecesarias crudezas que se observan en numerosos literatos jóvenes.

Huellas en la tierra, ${ }^{7}$ el primer tomo de cuentos que Castro nos en. tregó en I940, consituye una celebrada colección de relatos en que como muy bien se ha apuntado "brota un sentido intimo de cariño a la tierra". Era el terruño que el autor conocía y que le despertaba los sentimientos

- Alone, "Evocación de Oscar Castro", Atenea (Concepción, Chile), 1947, Nos. 269-270, pp. 420-428.

7 Huellas en la tierra (Santiago de Chile, Zig-Zag, 1940), 155 pp. Prólogo por Armando Bazán. 
y emociones, cuyos recuerdos imborrables y de variada estampa notamos a cada paso vertidos en sus narraciones. Ciñéndose al sencillo contorno del ambiente rural, entendiendo por ello todo lo que no es metropolitano y santiaguino, comunicando con un leguaje vitalizado las palpitaciones del conjunto hombre tierra y vislumbrando la variedad temática que surge con natural y graduado latido al comulgar los elementos humanos entre sí y la tierra con ellos, Castro pasea al lector por el amplio panorama de su ámbito artístico.

Sin artificios ni complicaciones, a base de una mera anécdota o de un sucinto escenario rebosante de vida y color, sin descuidar la fisonomía de la gente ni de la tierra misma, humanizada ésta por la idiosincracia del chileno de pura cepa, Castro deleita al lector con variados cuentos difíciles de olvidar. Allí conocemos al astuto viejo don Beño que confunde a la policía haciéndole creer que la mancha de sangre dejada en la cama por un criminal amigo, oculto en su choza, es vestigio de una aventura con una moza del lugar. Asistimos a la epopeya de Lucero, reve. ladora del estrecho vinculo que ata al hombre con su cabalgadura sin impedirle al mismo tiempo el sacrificio de su posesión más querida para dar cumplimiento a la palabra empeñada. Emocionante y tierna es la narración titulada El callejón de los gansos ya consagrada entre las creaciones más novedosas del autor por su forma y materia, originadas ambas en lo que es más espontáneamente auténtico del ambiente agreste de Chile. Cobra vida ese callejón de los gansos hasta convertirse en la figura central del cuento con tanta realidad y poético color como los humanos que en él pululan con sus cuitas y miserias. La ingratitud del patrón que nunca llega a comprender la amorosa raigambre que une al viejo campesino con su rancho es el tema de Tierra ajena, relato cuya ternura se prolonga en Chepa, la arisca hijastra que por fin cae vencida ante las bondades de su madre política.

No todo, sin embargo, es dulzura en la existencia rural y Castro oportunamente se hace cargo de ello. La familia, por ejemplo, a veces está lejos de constituir una célula social estable. Los hijos con facilidad abandonan el hogar tras la tentadora atracción que les brinda el dinero del Norte minero, las hijas sucumben con frecuentes "descuidos" y los patrones no se resisten a inmiscuirse, a veces con violencia, en la vida privada de la peonada.

La talla humana de los hijos de la tierra, por otra parte, se agiganta ante la adversidad: Roberto Cáceres, en Un bombre y un perro, padece cárcel y presiente la inevitable muerte de su perro, pero no por ello per- 
mite que a éste se le maltrate injustamente; Floridor Muñoz vuelve a las duras labores agrícolas pata no avergonzar a un pretencioso hijo suyo, próximo a casarse con una joven de la ciudad; Chumingo, sólo por complacer a su protector, soporta los ultrajes que le hace Rita al despedirlo de la casa en que vive de allegado, logrando al fin por su nobleza que la muchacha le corresponda en amores; Alberto Pedraza, con aparente brusquedad ordena el pronto matrimonio de una campesina, hija natural suya, con el seductor que pretendía abandonarla; el "Negro" Chávez cae acribillado por los sabuesos que lo persiguen y acusan de un crimen nunca por él cometido, pero muere con la satisfacción de haber utilizado la última bala que le quedaba en liquidar a su fiero enemigo, el sargento Gatica; don Sebastián Carreño perdona al hijo dilapidador y mentiroso porque resulta ser el más diestro y valiente huaso de un rodeo; José Ma. ría muere a manos de un tramposo tahur, peto con ello logra que su frívola novia vea la realidad y comprenda el sacrificio de su vida.

Si bien es cierto que los argumentos acusan poca originalidad y el enredo episódico parece relativamente débil, sin contar con que la temá. tica pudiera llegar a constituir con frecuencia un lugar común de la producción criollista, lo que llama la atención en los relatos de Castro es la sencillez del esquema expositivo, la forma directa en que se hace la presentación de los hechos y la impresionante brevedad de las descripciones humanas y paisajistas. El sentido poético de la naturaleza, cogido en su esencial pureza gracias a la fina sensibilidad de Castro y expuesto con precisión por el dominio que el escritor posee del lenguaje y de las técnicas literarias, junto con la ordenada organización que se observa en la trama, casi siempre ocultando un desenlace inesperado, son cualidades poco corrientes en los relatos criollistas, pero abundantes en Castro. Si se añade a esto el conocimiento que el autor posee de la materia, el cariño que comunica a su creación y despierta en el lector hacia la tierra y la gente que en ella habita, se llegará muy cerca de la medida que Cas. tro empleó en cada una de sus narraciones. La naturalidad de una vida rural corriente con todos sus altibajos en un medio bello por su esquemá. tico brillo constituyen los elementos angulares en que descansa la estruc. tura narrativa. A este marco quedan sujetos los conocimientos literarios y la capacidad artística del escritor. La adecuación del genio a la materia, el buen gusto y el poder de observación y captación que escoge lo medular de la historia humana en un medio escuetamente típico, interesante y atrayente dan las otras notas personales de esta colección de Oscar Castro. 
En 1944 apareció un segundo tomo de cuentos, La sombra de las cumbres, 8 en que figuran ocho narraciones algo distintas de las que acabamos de comentar. Aunque es el ambiente rural el que de nuevo sirve de fondo a la trama, se observa cierto afán del escritor por complicar el enredo narrativo y elaborar situaciones que a la postre se tornan un tanto artificiales. Predomina la acción o movimiento de los personajes sobre el breve, pero certeramente brillante mosaico paisajista que notá. bamos en Huellas en la tierra. Los personajes que ya no viven con desenvoltura y naturalidad, se ven ocasionalmente asaltados por las zozobras propias de una extraña existencia. Hay asedios constantes y casi obsesivos como recursos condicionantes de su conducta. Predominan sin contrapeso el erotismo y la violencia como fuentes principales y determinantes del comportamiento humano hasta llegar a hacer crisis en cuentos como $\mathrm{La}$ luz y la carne. En este relato un ministro del Señor violenta brutalmente a una campesina y con ello da la razón a un hermano suyo cuya lascivia el virtuoso sacerdote venía condenando con firme entereza. Siguiendo parecida orientación, con despiadada crudeza y notoria artificialidad, en el caso del idiota Moñi, a éste le maltrata bárbaramente un matón que no se detiene ante las más repulsivas inmundicias a fin de mofarse con saña del indefenso demente. $Y$ el conocido tema de la rivalidad de dos her. manos que aman a la misma joven y casi llegan a matarse en una reyerta, más el manoseado epílogo de la amada que pierde el cariño de ambos galanes, da pie a Castro en El valle y la moniaña para narrar una serie de episodios desprovistos de cohesión e interés.

La nota que atenúa el desequilibrio tonal de algunos de estos cuentos es la inclusión de ciertos atisbos folklóricos recogidos con sumo cuidado por Castro e incorporados casi siempre con tino y delicadeza en el desenlace dramático de sus relatos. Gracias a que echa mano de recursos de marcado tinte supersticioso, sobrenatural o fantástico, la historieta se aviva, deja una interrogante y añade colorido o emoción al ambiente y a los personajes. Descontada la inverosimilitud de los hechos mismos, queda en pie ese sabor popular de bien dosificada duda acerca de las meras apariencias fantásticas de ciertos episodios equívocamente irreales. Rodeada de misterio ocurre la muerte de Juan Alberto cuando en el recodo de Las Tres Animitas se le espanta el caballo y cae sin vida ma. lográndose la perspectiva que se le brindaba de gozar aquella noche de la apetecida campesina que había prometido rendírsele. Pero este $226 \mathrm{pp}$.

8 La sombra de las cumbres (Santiago de Chile, Editorial Orbe, 1944), 
dejo de vago misterio que con facilidad pudiera llevar a pensar en una simple casualidad se convierte en escenario macabramente fantástico en Antenor tiene sed. Aun cuando el elemento folklórico de la excursión de Antenor a un mundo satánico de brujos y demonios nos sirve para conocer en parte la tradición mitológica regional, su presentación no logra ubicarse en el plano artístico más deseable. Además de su carácter demasiado anecdótico, más parece la aliñada transcripción de lo que algún informante popular le contó al autor que la creación artística de un literato. Carece este relato de la atenuada y esporádica intervención de lo sobrenatural en la existencia de los personajes que se observa asimilada al relato de El último. La mayor elaboración de este último cuen. to se nota en que a las fabulosas historietas de Ciriaco Zúñiga se añade el aislamiento en que éste vive ejerciendo con suma pericia los oficios de carbonero y cestero. Es indudable que la soledad del personaje alimenta los risueños extravíos de su imaginación y le da una personalidad definida y simpática. Sin embargo, Castro pronto abandona esta ruta literaria para volver a su tema favorito: Ciriaco Zúñiga echa de menos la compañía de una hembra, la cual por fin llega extraviada al agreste paraje en que habita el protagonista y de inmediato hace pensar al lector en el desenlace del cuento. Los dos segmentos del relato se dan en forzada yuxtaposición. Las emocionantes alternativas de los pactos con el diablo y la falta de cumplimiento de éstos por la derrota física que se le inflinge al demonio no alcanzan a formar un tejido perfecto con el pro. blema de la insatisfacción de los instintos que experimenta Ciriaco en la soledad de su medio. Hay precipitación y descuido en la presentación y desarrollo del nudo estructural. La llegada de la joven es demasiado providencial para que pase por verosímil y la determinación de Ciriaco de hacerla su compañera es casi obvia a través del forzado soliloquio mental en que se debate al acurrucarse en los hornos, lejos de la joven a quien quisiera respetar siquiera por una noche.

Más esmero demuestra Castro en las pinceladas con que nos lleva a la imprevista decisión de Bautista Riquelme, El bombre que tallaba es. tribos, de marcharse del villorio en que vive, dejando a su querida Re. beca, convencido de que en verdad es responsable del extraño "mal de ojo" de que enferman y mueren algunos vecinos. La epopeya de Juan Crespo, por otra parte, es sin duda el cuento mejor compuesto de esta colección. El injusto encarcelamiento de Juan que lo lleva a convertirse en "ladrón generoso", personaje corriente en la literatura del campo chileno, queda en segundo plano y sirve sólo para apuntalar los momen- 
tos más ingeniosos que Castro incorpora al relato. La ya famosa invulnerabilidad de los foragidos que acompañan a Crespo no se revela hasta que acorralados por la justicia, el jefe de la banda se ve obligado a huir dejando a sus compañeros a merced de los que le persiguen. La sorpresa es mayúscula cuando se constata que los temidos maleantes de la comarca no son más que meros maniquíes. A este despliegue de talento, festivamente emocionante, el autor añade el perdón que se le concede a Juan y que lo salva en los precisos momentos en que el lector espera su suicidio, su arresto o quizás la muerte tras inevitable y sangrienta refriega con los carabineros que se le avecinan. Las variadas escenas con que sorpren. de la caprichosa geografía chilena, la diversidad episódica en consonancia con la agitada vida del "bandido", los inesperados desenlaces parciales y el final, así como el cuidado expresivo de Castro, son rasgos que elevan la calidad artística de este relato. Los únicos lunares que lo afean son la factura algo fragmentada de la composición y la moraleja temática que se añade en los renglones finales: Juan se casa con la hija de su defensor, trabaja honradamente y se convierte en acaudalado agricultor.

Aunque nuestro propósito principal ha sido poner de relieve algunos de los elementos artísticos con que Oscar Castro ha vigorizado la orien. tación criollista del cuento chileno, no podemos dejar de mencionar las otras composiciones que completan su labor literaria. Por caer dentro de la categoría novelesca, no han de buscarse en ellas los atributos que observábamos en los relatos más breves. Baste con indicar que en la $\mathrm{Co}$. marca del jazmin (1945) se ha visto una rarración rebosante de sensitividad y delicadeza que nos revela "los secretos de un alma infantil, que capitaliza alegrías y angustias a fuerza de ciego y lírico instinto, sobrevolando con sus anhelos los primeros contrafuertes de la vida".9

Llampo de sangre ${ }^{10}$ (1950), considerada entre las novelas más sobresalientes de ambiente minero, amplía el escenario ya antes apuntado en algunos cuentos, equilibrada mezcla de la realidad y fantasía, lucro y desinterés, brutalidad y justicia en que se debate la heterogénea vida minera de las serranías de Alhué. El abigarrado mosaico de encontradas personalidades que tapiza el campamento y bulle como colmenar acicateado por la ambiciosa meta de hacer realidad la ilusión de una leyenda

9 Citado por Francisco Dussuel, Historia de la literatura cbilena, Santiago de Chile, Ediciones Paulinas, 1954, pp. 118.

10 Llampo de sangre (Santiago de Chile, Imprenta Universitaria, 1950), 236 pp. La segunda edición y la tercera, de 1954 y 1957, fueron publicadas por la Editorial del Pacifico y llevan prólogo de Alejandro Magnet, "Oscar Castro, novelista póstumo". 
o una quimera, la fuerza avasalladora del brazo y el corazón del minero para conquistarse a sí mismo y vencer en el desafío que le tiende la madre tierra, así como la atmósfera primitivamente poética que respiran hombre y ambiente, dan los tonos más intensos de la narración episódica. Frag. mentada es ésta, como la incoherente y sinuosa existencia de los hombres del campamento y de la topografía chilena, pero por su individuali. dad brilla inconfundible, se nos antoja legendaria o mística y llega a materializarse con perfiles equívocos, originales y únicos.

Dos fueron las novelas que Castro dejó inéditas y que han aparecido póstumamente: La vida simplemente ${ }^{11}$ (I95 I) y Lina y su sombra ${ }^{12}$ (1958). La primera reproduce la ya conocida temática del burdel con todos sus arreos de crudeza y toques sentimentales, increíbles éstos y trillados aquéllos, aunque se hayan querido encontrar elementos autobiográficos en ambos. Parecida trayectoria de almibarado sentimentalismo y exacerbada bajeza sigue la última novela escrita por el autor rancagüino: historia de una joven provinciana "decente" que vive amancebada, sin que lo sepan sus padres, con un tahur burdo y despiadado, del cual se le hace difícil zafarse cuando se cansa de él y ve la conveniencia de corresponderle a un buen partido que se le of rece en "honesto" matri. monio. De toda la novela, en que a base de repetidas escenas predomina el afán por inclinar al lector a sentirse emocionalmente identificado con los "aproblemados" personajes, se salva la figura del "gringo" bonachón que ama con ternura y sinceridad a la caída y "acomplejada" Lina. La ingenuidad casi infantil del norteamericano, ladino en el fondo, práctico y diestro en su oficio y para enfrentarse con las adversidades de la vida, sin prejuicios hasta un grado incomprensible para la mentalidad criolla, y sobre todo generoso, quizás por la superioridad con que cuenta en un ambiente de estrecheces económicas y morales, son los rasgos que Castro escoge para que en último término sea este personaje quien determine el curso del relato. Castro acierta al delinear el perfil psicológico de este "gringo americano", añade una personalidad novedosa para la tipología novelesca chilena y contribuye a ampliar el conocimiento que los lectores de habla española quizás alcancen de algunos rasgos de la idiosincrasia angloamericana.

Si no es mucho lo que Castro aporta al perfeccionamiento de la novela chilena, con los cuentos que hemos comentado, consiguió establecer una nueva pauta literaria digna de ser tenida muy en cuenta en la evolu-

11 La vida simpiemente (Santiago de Chile, Nascimiento, 1951), 396 pp.

12 Lina y su sombra (Santiago de Chile, Zig-Zag, 1958), 244 pp. 
ción del criollismo. El equilibrio estructural y el sentido de las proporciones, dentro de los escasos límites que of rece el cuento, así como el cuidado en la elaboración de un fondo ambiental y de personajes que el autor conocía en todas sus dimensiones, y por ende pudo pintar con absoluta seguridad, llevan a Castro, por lo general, a trabar bien los episodios, a desenvolver la trama con originalidad y esmero, a dar colorido y lustre al viviente conjunto hombre-tierra y a acentuar el sentido de sobriedad del contenido y la expresión que tanto echamos de menos en otros criollistas. Las imperfecciones que tal vez notemos en la factura de sus relatos, en la caracterización de sus personajes o en el desenvol. vimiento de la trama, sin duda servirán a los cultores de la nueva orientación para seguir mejorando la calidad de sus obras. Por ese derrotero se irá desembocando en el mundo literario americano que ya empieza a aflorar con la inconfundible diversidad vital de su variada gama humano. ambiental.

Homero Castillo ..

Nortbwestern University

Evanston, Illinois 